\title{
Estimação de parâmetros genéticos para características produtivas em búfalos na Amazônia Oriental
}

[Estimation of genetic parameters of dairy buffaloes productive characteristics Eastern Amazon]

\author{
A.E. Rodrigues ${ }^{1}$, J.R.F. Marques ${ }^{2}$, C.V. Araújo ${ }^{3}$, R.N.C. Camargo Júnior ${ }^{4}$, L.N.S. Dias ${ }^{5}$ \\ ${ }^{1}$ Universidade Federal Rural da Amazônia \\ Caixa Postal 917 \\ 66077-530 - Belém, PA \\ ${ }^{2}$ Embrapa Amazônia Oriental - Belém, PA \\ ${ }^{3}$ Universidade Federal de Mato Grosso -Sinop, MT \\ ${ }^{4}$ Instituto Federal de Educação, Ciência e Tecnologia do Pará - Santarém, PA \\ ${ }^{5}$ Aluno de pós-graduação - UFPA - Belém, PA
}

\begin{abstract}
RESUMO
Dados de 1.182 registros de produção de fêmeas bubalinas da raça Murrah e seus mestiços, parindo no período de 1967 a 2005, foram utilizados para estimação de parâmetros genéticos utilizando-se o método de máxima verossimilhança restrita. O modelo animal utilizado para estimação de componentes de variância incluiu os efeitos fixos de rebanho, ano e época de parto, ordem de parto e duração da lactação e os efeitos aleatórios do animal, e ambiente permanente e temporário. As estimativas de herdabilidade foram 0,25, 0,18, 0,08 e 0,09, para produção de leite, produção de gordura, duração da lactação e produção de leite por dia de intervalo de parto, respectivamente. As estimativas de repetibilidade foram 0,33, 0,29 e 0,10 para produção de leite, produção de gordura e duração da lactação, respectivamente. As correlações genéticas entre produções de leite e gordura, produção de leite com duração da lactação, produção de leite com produção de leite por dia de intervalo de partos, produção da gordura com duração da lactação, produção de gordura com produção de leite por dia de intervalo de partos e duração da lactação com produção de leite por dia de intervalo de partos foram 0,$93 ; 0,76 ; 0,99 ; 0,89 ; 0,87$ e $-0,27$, respectivamente. Os resultados demonstram que ganhos genéticos podem ser obtidos pela seleção das produções de leite e gordura.
\end{abstract}

Palavras-chave: búfalo, leite, melhoramento genético, herdabilidade, repetibilidade

\begin{abstract}
Data from 1,182 records of Murrah females buffaloes and their crossbreds, calving from 1967 to 2005 , were used to estimate genetic parameters by maximum restricted likelihood method. An animal model used to estimate variance components, included the fixed effects of herds, year and season of calving, order of parity, and length of lactation as covariables; and random effects of animal, permanent, and temporary environment. The estimate of heritability to milk yield, fat yield, length of lactation, and milk yield per day of calving interval were 0.25, 0.18, 0.08, and 0.09 respectively. Estimate of repeatability for milk yield, fat yield, and length of lactation were 0.33, 0.29, and 0.10, respectively. The genetic correlations between milk yield and fat yield, milk yield and length of lactation, milk yield and milk yield per day of calving interval, fat yield and length of lactation, fat yield and milk yield per day of calving interval, and length of lactation and milk yield per day of calving interval were 0.93, 0.76, 0.99, 0.89, 0.87 , and -0.27 , respectively. These results showed that genetic gains may be obtained by selecting to milk and fat yields.
\end{abstract}

Keywords: buffalo, milk, animal breeding, heritability, repeatability

Recebido em 13 de novembro de 2009

Aceito em 10 de junho de 2010

E-mail: ale.epifanio@yahoo.com.br 


\section{INTRODUÇÃO}

Nos últimos 10 anos, o rebanho bubalino mundial apresentou taxa de crescimento de 7,8\%, a produção de leite desta espécie aumentou 28,3\% (FAO, 2005). Mas, como ocorre nas demais espécies de interesse zootécnico, o crescimento do rebanho bubalino deve estar associado ao controle da produtividade, o que possibilita a identificação dos animais que possuem mérito genético, e multiplicação e distribuição dos animais melhoradores, com o auxílio das biotecnologias da reprodução. Dessa forma, a bubalinocultura, hoje, é responsável por $12,4 \%$ da produção mundial de leite (FAO, 2005) e pode se tornar uma atividade econômica cada vez mais atraente.

Na Amazônia, a criação de búfalos é feita de forma semiextensiva à extensiva, em ecossistemas de pastagens nativas e cultivadas, onde são criadas com maior expressividade as raças Murrah e Mediterrâneo e, em menor número, as raças Carabao e Jafarabadi (Lodovino, 1996). A raça Carabao e o tipo Baio (que não é considerado raça pela Associação Brasileira de Criadores de Búfalos - ABCB) ainda são encontrados na ilha de Marajó, contudo, segundo Cassiano et al. (2003), ambos estão em risco de extinção e descaracterização.

Embora existam trabalhos, realizados no país, sobre as características produtivas e reprodutivas dos bubalinos (Tonhati et al., 2000; Cassiano et al., 2003; Tonhati et al., 2004), ainda há carência de informações sobre estimativas dos parâmetros genéticos nesta espécie. Associado a isso, o conhecimento do progresso genético alcançado pelos diferentes rebanhos é desconhecido, tanto pelos criadores que realizam a seleção de maneira empírica, como por aqueles que participam de programas de melhoramento genético (Ramos et al., 2006).

O objetivo deste trabalho foi estimar parâmetros genéticos, incluindo correlações genéticas, herdabilidade e repetibilidade para características produtivas em búfalos na Amazônia Oriental.

\section{MATERIAL E MÉTODOS}

Os registros analisados foram provenientes de controle de produção e colhidos no período de
1967 a 2005. Após editoração dos dados, considerou-se para estudo 1.182 registros de fêmeas bubalinas da raça Murrah e seus mestiços. Todos os animais possuíam registro genealógico, possibilitando, assim, o seu controle genético dos mesmos.

Os rebanhos de bubalinos estudados pertencem à Unidade de Pesquisa de Bubalinos "Dr. Felisberto Camargo" e ao Banco de Germoplasma Animal da Amazônia Oriental de propriedade da Embrapa Amazônia Oriental, localizado em Belém - PA.

Os animais eram manejados em regime de pastejo contínuo e rotacionado intensivo, em pastagens nativas de terra inundável, em cuja composição botânica predominava o gênero Echinochloa, e pastagens cultivadas de Brachiaria brizanta, Brachiaria humidicola e Panicum Maximum (Tobiatã), onde permaneciam por, aproximadamente, três dias, em cada piquete. Todos os animais recebiam suplementação mineral durante todo o ano. O controle sanitário era realizado periodicamente no rebanho, com exames e diagnósticos para brucelose e tuberculose, além de vacinação de todos os animais contra febre aftosa e das fêmeas entre três e oito meses contra brucelose.

Para estimação de componentes de (co) variância e de parâmetros genéticos para produção de leite, produção de gordura, duração da lactação e produção de leite por dia de intervalo de parto, foi utilizado o método de máxima verossimilhança restrita, sendo processados por meio de análises bicaracterísticas (duas em duas). Posteriormente, predisseram-se os valores genéticos dos animais por meio das soluções das equações do modelo misto. Todas as análises foram obtidas por meio do programa Multiple Trait Derivative Free Restricted Maximum Likelihood (MTDFREML), desenvolvido por Boldman et al. (1995).

A análise utilizada para obtenção de componentes de (co) variância, levando-se em conta a distribuição conjunta das características, empregou o seguinte modelo:

$$
y_{i}=X_{i} \beta_{i}+Z_{i} a_{i}+W_{i} p_{i}+e_{i}, \text { sendo: }
$$


$y_{i}=\left[\begin{array}{l}y_{1} \\ y_{2}\end{array}\right], \quad X_{i}=\left[\begin{array}{cc}X_{1} & 0 \\ 0 & X_{2}\end{array}\right], \quad \beta_{i}=\left[\begin{array}{l}\beta_{1} \\ \beta_{2}\end{array}\right], Z_{i}=\left[\begin{array}{cc}Z_{1} & 0 \\ 0 & Z_{2}\end{array}\right]$,
$a_{i}=\left[\begin{array}{l}a_{1} \\ a_{2}\end{array}\right], \quad W_{i}=\left[\begin{array}{cc}W_{1} & 0 \\ 0 & W_{2}\end{array}\right], \quad p_{i}=\left[\begin{array}{l}p_{1} \\ p_{2}\end{array}\right]$ e $e_{i}=\left[\begin{array}{l}e_{1} \\ e_{2}\end{array}\right]$, em que:

$\mathrm{y}_{\mathrm{i}}=$ vetor das observações da características $\mathrm{i}$, com $\mathrm{i}=1$ e 2 (onde os índices 1 e 2 representam as combinações entre as características produção de leite, produção de gordura, duração da lactação e produção de leite por dia de intervalo de parto); $\beta_{\mathrm{i}}=$ vetor dos efeitos fixos da i-ésima característica; $a_{i}$ vetor de efeitos genéticos diretos aditivo do animal na i-ésima característica; $p_{i}$ vetor de efeitos de ambiente permanente na $i$ ésima característica; $e_{i}$ vetor de efeitos residuais referente à i-ésima característica; $\mathrm{X}_{\mathrm{i}}, \mathrm{Z}_{\mathrm{i}}, \mathrm{e} \mathrm{W}_{\mathrm{i}}$ referem-se às matrizes de incidência de efeitos fixos, genético direto e de ambiente permanente, respectivamente, na i-ésima característica.

Admitindo-se que $\mathbf{y}, \mathbf{a}, \mathbf{p}$ e e tenham distribuição normal multivariada, as pressuposições acerca do modelo foram:

$$
\left[\begin{array}{c}
y \\
a \\
p \\
e
\end{array}\right] \sim\left\{\left[\begin{array}{c}
X \beta \\
\phi \\
\phi \\
\phi
\end{array}\right],\left[\begin{array}{cccc}
Z G Z+W P W+R & Z G & W P & R \\
G Z & G & \phi & \phi \\
P W & \phi & P & \phi \\
R & \phi & \phi & R
\end{array}\right]\right\},
$$

em que $\mathbf{G}=\mathbf{A} \otimes \mathbf{G}_{\mathbf{0}}, \mathbf{P}=\mathbf{I}_{\mathbf{n}} \otimes \mathbf{P}_{\mathbf{0}}$ e $\mathbf{R}=\mathbf{I}_{\mathbf{n}} \otimes \mathbf{R}_{\mathbf{0}}$, sendo: $A=$ matriz de numerador do coeficiente de parentesco entre os indivíduos, $\mathbf{G}_{0}=$ matriz de variâncias e covariância genética aditiva entre as características 1 e $2 ; \mathbf{P}_{\mathbf{0}}=$ matriz de variâncias do efeito de ambiente permanente entre as características 1 e $2 ; \mathbf{P}_{\mathbf{0}}=$ matriz de variâncias do efeito de ambiente temporário entre as características 1 e $2 ; \mathbf{I}_{\mathbf{n}}$ é a matriz identidade, de ordem igual ao número de observações e $\bigotimes$ é o operador produto direto.

Para as características produção de leite e de gordura, foram considerados como efeitos fixos rebanho, ano e época de parto, o grupo genético e a ordem de parto do animal, além da covariável duração da lactação, sendo que a covariável foi omitida quando a análise bicaracterística envolveu a duração da lactação como variável resposta. Para a produção de leite por dia de intervalo de parto, foi desconsiderado o efeito de ambiente permanente, por ter havido confundimento com o efeito genético direto.

A correlação de Spearman entre os valores genéticos preditos para cada característica, editoração e montagem de arquivos necessários para as análises foram feitas pelo sistema SAS/2002, em que foram analisadas as características: produção de leite (PL), produção de gordura (PG), duração da lactação (DL) e produção de leite por dia de intervalo de parto (PLDIDP).

\section{RESULTADOS E DISCUSSÃO}

As médias observadas para produção de leite, produção de gordura, duração da lactação e produção de leite por dia de intervalo de parto foram $1.663,84 \pm 383,60, \quad 116,84 \pm 29,71$, $269,89 \pm 56,36$ e $3,88 \pm 1,15$, respectivamente, sendo mais altas que a encontradas em búfalos por Marques (1991), Tonhati et al. (2000), Duarte (2002), Jorge et al. (2005), que relataram médias de $1.171,68 \pm 253,67 \mathrm{~kg}$, $86,12 \pm 33,84 \mathrm{~kg}, \quad 226,14 \pm 28,53$ dias e $3,75 \pm 1,23 \mathrm{~kg}$, respectivamente.

As estimativas de covariância genética aditiva, de ambiente permanente, ambiente temporário, herdabilidades e repetibilidades para as características estão descritas na Tab. 1 .

A estimativa de herdabilidade para produção de leite foi mais alta que as observadas por Tonhati et al. (2000), Catillo et al. (2002) e Ramos et al. (2006), que estimaram herdabilidades de 0,24, 0,19 e 0,21 , respectivamente. O valor estimado para a herdabilidade reflete considerável variação genética aditiva entre os indivíduos em relação às características estudadas. Valores superiores foram relatados por Gogoi et al. (1985) e Taylor e Jain (1987), que estimaram coeficiente de herdabilidade para a característica de 0,37 e 0,55 , respectivamente. 
Tabela 1. Componente de covariância, herdabilidade $\left(h^{2}\right)$ e repetibilidade (r) para produção de leite (PL), produção de gordura (PG), duração da lactação (DL) e produção de leite por dia de intervalo de parto (PLDIDP) em bubalinos

\begin{tabular}{llllll} 
Característica & $\sigma^{2} \mathrm{a}$ & $\sigma^{2} \mathrm{pe}$ & $\sigma^{2} \mathrm{e}$ & $\mathrm{h}^{2}$ & $\mathrm{r}$ \\
\hline PL & $103.207,38$ & $37.428,55$ & $274.705,86$ & 0.25 & 0.33 \\
PG & 304,9 & 109,01 & $1.195,45$ & 0.18 & 0.29 \\
DL & 544,38 & 113,41 & $5.667,32$ & 0.08 & 0.10 \\
PLDIDP & $1,09-1,20$ & & $1,16-1,17$ & 0.09 & \\
\hline
\end{tabular}

$\sigma^{2}$ a: variância genética aditiva; $\sigma^{2}$ pe: variância de ambiente permanente; $\sigma^{2} e$ : variância de ambiente temporário; $h^{2}$ : herdabilidade; r: repetibilidade.

Relacionado as estimativas dos coeficientes de herdabilidade para a característica produção de leite, observa-se que, na literatura, em função dos diferentes métodos, populações, épocas e regiões, os valores são bastante diferenciados.

A estimativa de herdabilidade para produção de gordura foi mais alta que a relatada por Rosati e Van Vleck (2002), que estimaram 0,11. Por outro lado, Duarte (2002) estimou herdabilidade de 0,24 para essa característica.

A herdabilidade para a duração da lactação foi maior que a observada por Tonhati et al. (2000) de 0,01. Entretanto, em estudos realizados na Índia, Taylon e Jain (1987) relataram herdabilidade de 0,26 para duração da lactação.

$\mathrm{Na}$ produção de leite por dia de intervalo de parto, o valor estimado de herdabilidade foi menor que os observados por Vij (1986), Sharma e Sing (1990) e Marques (1991), que relataram herdabilidades de 0.26, 0.29, e 0.26 , respectivamente.

A repetibilidade estimada para produção de leite de 0,33 foi semelhante à relatada por Ramos et al. (2006), que estimaram repetibilidade de 0,32.
Tonhati et al. (2004) relataram, para essa característica, estimativa de repetibilidade de 0,41. Segundo Ramos et al. (2006), a magnitude da repetibilidade indica a possibilidade de se utilizar as primeiras produções das búfalas como indicativo de sua produção futura, e de se escolher, assim, as fêmeas que continuarão no rebanho.

A característica produção de gordura apresentou repetibilidade de 0.29. Marques (1991) reportou repetibilidade para produção de gordura de 0.45 . Tonhati et al. (2000) estimaram coeficiente de repetibilidade para produção de gordura de 0,28.

A correlação de Spearman, com base nos valores genéticos preditos para produção de leite, produção de gordura, duração da lactação e produção de leite por intervalo de parto, encontra-se na Tab. 2. Os melhores animais classificados para produção de leite são também os melhores para as demais características estudadas.

As correlações genéticas para produção de leite, produção de gordura, duração da lactação e produção de leite por dia de intervalo de parto estão descritas na Tab. 3.

Tabela 2. Correlação de Spearman com base nos valores genéticos preditos para produção de leite (PL), produção de gordura (PG), duração da lactação (DL) e produção de leite por dia de intervalo de parto (PLDIDP)

\begin{tabular}{lcccc} 
Características & PL & PG & DL & PLDIDP \\
\hline PL & 1.00 & 1.00 & & \\
PG & 0.94 & 0.84 & 1.00 & \\
DL & 0.81 & 0.97 & 0.85 & 1.00 \\
PLDIDP & 0.96 & & & \\
\hline
\end{tabular}


Tabela 3. As correlações genéticas para produção de leite (PL), produção de gordura (PG), duração da lactação (DL) e produção de leite por dia de intervalo de parto (PLDIDP)

\begin{tabular}{cccccc}
\hline Características & PL & PG & DL & \multicolumn{2}{c}{ PLDIDP } \\
\hline PL & & 0.93 & 0.76 & 0.99 \\
PG & & 0.89 & 0.87 \\
DL & & & & -0.27 \\
\end{tabular}

Os valores estimados de correlações genéticas entre as características: produção de leite e produção de gordura; produção de leite e duração da lactação; produção de leite e produção de leite por dia de intervalo de parto foram de 0,93, 0,76 e 0,99, respectivamente, ou seja, ao usar a produção de leite como critério de seleção, espera-se promover simultaneamente a seleção para maior produção de gordura e maior produção de leite por dia de intervalo de parto.

Duarte (2002) observou estimativa de correlação genética entre produção de leite e produção de gordura de 0,66. Em estudo realizado na Itália, Rosati e Van Vleck (2002) reportaram uma correlação genética para tais características de 0,88 . O alto coeficiente de correlação entre produção de leite e produção de gordura revela que grandes partes dos genes que afetam a produção de leite também afetam a produção de gordura.

A correlação genética entre produção de leite e duração da lactação foi de 0,76 e a entre produção de gordura e duração da lactação foi de 0,89 . Tais estimativas revelam que a seleção para o aumento da produção de leite também promove aumento na duração da lactação e na produção de gordura.

A correlação genética entre produção de leite e duração da lactação observada neste trabalho foi inferior às relatadas por Singh et al. (1989) e Tonhati et al. (2004), de 0,90 e 0,96 a 1,00, respectivamente.

As correlações genéticas observadas neste trabalho foram altas e positivas para a maioria das características estudadas, com exceção da correlação genética entre duração da lactação e produção de leite por dia de intervalo de parto que foi baixa e negativa na população estudada. Assim, infere-se que os genes envolvidos na duração da lactação não são os mesmos para a produção de leite por dia de intervalo de parto.

\section{CONCLUSÕES}

No rebanho estudado, existe considerável variabilidade genética aditiva para as características estudadas, que pode ser utilizada para promover o melhoramento genético do rebanho.

\section{REFERÊNCIAS BIBLIOGRÁFICAS}

BOLDMAN, K.G.; KRIESE, L.A.; VAN VLECK, L.D. et al. A manual for use of MTDFREML: A set of programs to obtain estimates of variances and covariances [DRAFT]. Lincoln: Agricultural Research Service, 1995. 120p.

CASSIANO, L.A.P.; MARIANTE, A.S.; MCMANUS, C. et al. Caracterização fenotípica de raças bubalinas nacionais e do tipo Baio. Pesq. Agropec. Bras., v.38, p.1337-1342, 2003.

CATTILO, G.; MACCIOTTA, N.P.P.; CARRETTA, A. et al. Effects of age and calving season on lactation curves of milk production traits in Italian Water buffaloes. J. Dairy Sci., v.85, p.1298-1306, 2002.

DUARTE. J.M.C. Estimativa de parâmetros genéticos e fenotípicos da produção $e$ constituintes do leite em bubalinos. 2002. 55f. Dissertação (Mestrado) - Faculdade de Ciências Agrárias e Veterinárias, Universidade Estadual Paulista, Jaboticabal.

FAO. FAOSTAT: Agriculture data. Disponível em:

Http://faostat.fao.org/faostat/collections?versio=e xt\&hasbulk $=0 \&$ subset $=$ agriculture. Acessado em: 30 abr.2005.

GOGOI, P.K.; JOHAR, K.S.; SINGH, A. Genetic analysis of milk yield in murrah buffaloes. Indian Vet. J., v.62, p.970-975, 1985. 
JORGE, A.M.; ANDRIGHETTO, C.; STRAZZA, M.R. et al. Correlação entre o California mastitis test (CMT) e a contagem de células somáticas (CCS) do leite de búfalas Murrah. Rev. Bras. Zootec., v.34, p.2039- 2045, 2005.

LODOVINO, R.M.R. Agricultura e pecuária em manejo (Pará-Brasil): diagnóstico dos sistemas de produção da agricultura familiar. 1996. 174f. Dissertação (Mestrado) - Instituto Superior de Agronomia Lisboa, Universidade Técnica de Lisboa, Portugal.

MARQUES, J.R.F. Avaliação genéticoquantitativa de alguns grupamentos raciais de bubalinos (Bubalus bubalis L.). 1991. 148f. Tese (Doutorado) - Faculdade de Medicina Veterinária e Zootecnia, Universidade Estadual Paulista, Botucatu.

RAMOS, A.A.; MALHADO, C.H.M.; CARNEIRO, P.L.S. et al. Caracterização fenotípica e genética da produção de leite e do intervalo entre partos em bubalinos da raça Murrah. Pesq. Agropec. Bras., v.41, p.12611267, 2006.

ROSATI, A.; VAN VLECK, L.D. Estimation of genetic parameters for milk, fat, protein and Mozzarela cheese production for the Italian river buffalo(Bubalus bubalis) population. Livest. Prod. Sci., v.74, p.185-190. 2002.
SHARMA, R.C.; SINGH, B.P. Genetic studies on Murrah buffaloes in livestock farms in Uthar Pradesh. In: WORD BUFFALO CONGRESS, 2., 1988, N. Delhi. Proceedings..., N. Delhi, 1990. p.128-133.

SINGH, C.V.; SINGH, R.V.; SINGH, S.P. Different aspects of milk production efficiency in nili-ravi buffaloes. Indian J. Anim. Sci., v.59, p.1161-1164, 1989.

TAYLOR, S.P.; JAIN, L.S. Genetic studies on production traits medium sized buffaloes. Indian J. Anim. Sci., v.57, p.771-774, 1987.

TONHATI, H.; MUÑOZ, M.F.C.; OLIVEIRA, J.A. et al. Parâmetros genéticos para a produção de leite, gordura e proteína em bubalinos. Rev. Bras. Zootec., v.29, p.2051-2056, 2000.

TONHATI, H.; CERON-MUÑOZ, M.; DUARTE, J. et al. Estimates of correction factors for lactation lenght and genetic parameters for milk yield in buffaloes. Arq. Bras. Med. Vet. Zootec., v.56, p.251-257, 2004.

VIJ, P.K. Phenotypic and genetic parameters of some production traits in buffaloes. Indian Vet. J., v.63, p.838-845, 1986. 